\title{
A IMUNIZAÇÃO CONTRA A RUBÉOLA NO PRIMEIRO TRIMESTRE DE GESTAÇÃO PODE LEVAR À PERDA AUDITIVA?
}

\author{
Can the immunization against rubella take to the hearing loss \\ in the first pregnancy quarter?
}

\author{
Ana Lúcia Pereira de Andrade Dias ${ }^{(1)}$, Edson Ibrahim Mitre ${ }^{(2)}$
}

\begin{abstract}
RESUMO
Tema: embora o risco da Síndrome da Rubéola Congênita após a imunização seja pequeno, é necessário assegurar a imunidade das mulheres em idade fértil, especialmente daquelas com risco mais alto de exposição, visando a prevenção. Objetivo: esclarecer o risco que a imunização da rubéola apresenta para a audição do recém nascido, no primeiro trimestre de gestação. Conclusão: os levantamentos realizados por este estudo permitiram concluir que ainda há um grande caminho a ser percorrido em prol da erradicação da rubéola no Brasil, bem como a diminuição dos riscos de surdez neurossensorial causados pela Síndrome da Rubéola Congênita.
\end{abstract}

DESCRITORES: Imunização; Rubéola; Gravidez

\section{INTRODUÇÃO}

No Brasil, atualmente, a rubéola ainda é uma doença que acomete gestantes podendo gerar variadas lesões no concepto, e entre elas encontram-se uma grande incidência de deficiência auditiva adquirida no período gestacional ${ }^{1-3}$.

A rubéola é a mais importante causa pré-natal da deficiência auditiva severa infantil, sendo responsável por $74,0 \%$ das etiologias congênitas. No Brasil, a incidência da surdez adquirida no período gestacional tem aumentado devido à piora das condições de saúde e falta de prevenção das principais doenças infecto-contagiosas ${ }^{3}$.

Campanhas de vacinação reduziram drasticamente os índices da infecção congênita por rubéola. $\mathrm{Na}$ tentativa de erradicar a doença, os programas de vacinação no Brasil e no mundo são implementados ressaltando a importância da imunização da rubéola em crianças e jovens, principalmente do sexo feminino. Ainda associados a eles se realizam os programas de conscientização sobre a doença,

(1) Fonoaudióloga; Hospital e Maternidade São José; Mestre em Fonoaudiologia pela Pontifícia Universidade Católica de São Paulo.

(2) Médico Otorrinolaringologista; Segundo Assistente da Santa Casa de Misericórdia de São Paulo, SCMSP, São Paulo, SP; Doutor em Medicina pela Faculdade de Ciências Médicas da Santa Casa de São Paulo. para que toda a população seja conscientizada da importância de sua prevenção e as consequências da Síndrome da Rubéola Congênita - SRC para o feto ${ }^{4}$.

Entretanto sabe-se que existe a contra-indicação da imunização da rubéola em gestantes e a prática de aconselhamento sobre a prevenção da gravidez logo após a imunização.

Durante as campanhas de vacinação contra a rubéola organizada pelo Ministério da Saúde ainda existe uma grande preocupação em relação às mulheres que recebem a vacina inadvertidamente no ciclo gravídico-puerperal.

Baseado nestas informações, o objetivo deste trabalho foi esclarecer o risco que a imunização da rubéola no primeiro trimestre de gestação apresenta para a audição do recém nascido.

\section{MÉTODOS}

Foram realizados os levantamentos de fontes secundárias de 1943 a 2003, observando o tema em questão, (livros de perinatologia e audiologia clínica; sites de publicações técnico-científicas em português e inglês sobre rubéola, SRC, vacinas e tratamentos; artigos e revistas científicos sobre o assunto) com posterior seleção, leitura sistemática, análise e compilação dos dados para serem inseridos neste trabalho. 
Foram utilizados os descritores da lista de "Descritores em Ciências da Saúde - DECs publicada pela Bireme, disponível na bibliotecas médicas e na homepage da BIREME http//:www.bireme.br.

Foi realizada uma análise crítica e comparativa dos textos selecionados, com ênfase nos métodos e resultados descritos, sobretudo com relação ao objeto deste estudo.

\section{REVISÃO DA LITERATURA}

A rubéola congênita foi identificada em 1815 e caracterizada como uma doença benigna em 1866 , porém só foi descrita em 1887. Inicialmente a rubéola era considerada variante de sarampo ou escarlatina sendo conhecida como uma terceira doença ${ }^{1}$.

O período de primavera ao verão, de setembro de 1940 a fevereiro de 1941, foi marcado por uma epidemia severa de rubéola na Austrália. A propagação desta infecção foi muito rápida, devido às condições do momento de guerra em que a aglomeração de jovens em campos militares fornecia um ambiente de susceptibilidade e uma situação que favorecia a transmissão ${ }^{5}$.

Diante desta epidemia, ficou marcado o início de preocupação com a rubéola por parte das comunidades médicas, após estudos de alterações teratogênicas realizados pelo cirurgião oftalmologista sênior do Royal Alexandra Hospital for Children, Dr. Norman MacAllister Gregg. Este registrou em 1941 a ocorrência de cataratas congênitas em 68 crianças nascidas de mães que adquiriram rubéola no início da gravidez. Este foi o primeiro caso conhecido de SRC ${ }^{6}$.

Os efeitos da rubéola congênita na audição de crianças infectadas ainda não foram mencionados nesta ocasião, pois a maioria das crianças investigadas estavam com 18 meses de idade. Desta forma a deficiência auditiva poderia ser negligenciada, principalmente na presença de outras alterações observadas ao nascimento ${ }^{5,6}$.

Dois anos depois, Charles Swan reportou a surdez neurossensorial em crianças afetadas por rubéola materna. Estudos como o de Swan et al (1944), Fox and Bortin (1946) e Clayton Jones (1947) foram os primeiros a registrar a associação entre a rubéola materna e defeitos auditivos ${ }^{6}$.

$O$ vírus da rubéola foi primeiramente isolado em 1962 por Parkman e Weller e constatou-se que a rubéola é causada por um vírus pleomorfo de RNA atualmente incluído na família Togaviridae, gênero Rubivirus ${ }^{2}$.

A rubéola é uma doença viral moderadamente contagiosa, que se caracteriza pela erupção na pele, inflamação das glândulas e, especialmente nos adultos, dores nas articulações. Em geral, a erupção na pele dura cerca de três dias e pode vir acompanhada de ligeira febre ${ }^{2,7}$. Outros sintomas como dores de cabeça e/ou garganta podem vir associados, e $20 \%$ a $50 \%$ das infecções de rubéola são assintomáticas ${ }^{4}$.

A transmissão da rubéola ocorre através das vias respiratórias (pelas gotículas de Flugue) por perdigotos, urina, líquido amniótico e placenta. Logo após o contágio com o vírus, ocorrerá um período de incubação de duas a três semanas antes do aparecimento dos sintomas. O contágio a outras pessoas se produz um ou dois dias antes da erupção da pele até uma semana depois ${ }^{8}$.

A mais séria consequência resultante da infecção da rubéola ocorre durante o primeiro trimestre de gestação. A rubéola materna pode cursar como uma infecção isolada, sem comprometimento fetal. Por outro lado, pode ser causadora de anomalias congênitas, reabsorção do embrião, aborto espontâneo e parto de natimorto ${ }^{2,6,9}$.

O vírus da rubéola infecta a placenta e é transmitida para o feto, disseminando-se para múltiplos órgãos e tecidos. O efeito do vírus depende do momento de sua infecção, quanto mais próximo da concepção maior é o dano produzido ${ }^{9}$. Estimase que o risco fetal é cerca de 80 a $90 \%$ quando a infecção ocorre no primeiro mês de gestação, provocando alterações graves ou aborto espontâneo. Durante o segundo e terceiro mês esta incidência decresce para 40 a $60 \%$ e 30 a $35 \%$ respectivamente. No quarto mês de gestação, os riscos não ultrapassam a $10 \%{ }^{6,8}$.

$\mathrm{O}$ vírus da rubéola tem um efeito denominado como citolítico, com habilidade de inibir o crescimento e maturação da célula. $O$ primeiro efeito no desenvolvimento do feto consiste na redução da taxa de desenvolvimento e divisão celular. Esta inibição altera o crescimento e desenvolvimento de todos os sistemas do organismo. O efeito citolítico do vírus da rubéola tem sido observado no miocárdio, cóclea e olhos ${ }^{10,11}$.

O período crítico de aquisição da rubéola é da $4^{\mathrm{a}}$ a $8^{\mathrm{a}}$ semana de gestação, época da organogênese e desenvolvimento do sistema auditivo 10-12. $\mathrm{Na} 20^{\mathrm{a}}$ semana de gestação a cóclea já se apresenta semelhante a de um adulto, e entre a $20^{\mathrm{a}}$ e a $30^{\text {a }}$ semanas ocorre o desenvolvimento funcional, ou seja, o feto inicia a aquisição das habilidades auditivas e passa a armazenar sons que podem ser reconhecidos após o nascimento (como a voz da mãe). Durante este período, o sistema auditivo fica mais sensível a infecções, podendo sofrer alterações indesejadas ${ }^{12,13}$.

Crianças que são moderadamente ou severamente afetadas pela SRC são prontamente reco- 
nhecidas ao nascimento, mas em outros casos como na surdez, pode ser descoberto meses ou anos após o nascimento ${ }^{14}$.

Os primeiros anos de vida de uma criança são extremamente importantes para o desenvolvimento das habilidades auditivas e da linguagem, pois 0 processo de maturação do sistema nervoso central ocorre mais intensamente no primeiro ano de vida, em virtude de ser um período de grande plasticidade, em que a experiência auditiva é fundamental para o desenvolvimento normal da audição e da linguagem. $O$ desenvolvimento normal da audição faz com que a criança apresente condições de desenvolver a comunicação oral, interagindo, consequentemente, com o mundo a sua volta também de maneira normal ou plena ${ }^{15}$.

A deficiência auditiva na SRC, geralmente envolve o ouvido interno, sendo mais frequente a ocorrência de lesão na estria vascular, membrana de Reissner e membrana tectória, levando a deficiência auditiva neurossensorial uni ou bilateral, sendo a maioria das vezes bilateral, de grau severo para profundo $3,10,12$.

Com menor frequência pode ser observada a deficiência auditiva central, caracterizada por lesão do córtex cerebral e ouvido interno íntegro, com variação na configuração audiométrica ${ }^{3}$.

Em estudo realizado na USP de Bauru, analisando 101 prontuários de pacientes com deficiência auditiva decorrente da rubéola congênita, constatou-se que todos eles apresentaram perdas auditivas neurossensoriais, e um maior número de pacientes apresentaram perda auditiva de grau severo a profundo. Entretanto, ainda foram encontrados, em menor índice, perdas auditivas de grau leve e moderado. Constatou-se ainda que dos pacientes deficientes auditivos, $13,8 \%$ adquiriram a rubéola durante o primeiro mês gestacional, $42,6 \%$ no segundo mês e $30,7 \%$ no terceiro mês, $12,9 \%$ adquiriram a rubéola do quarto ao sétimo mês gestacional ${ }^{16}$.

O Center for Diseases Control (CDC) estimou a ocorrência de 20.000 casos de SRC no período de 1964-1965, durante a última epidemia de rubéola nos EUA, antes que a vacina da rubéola se tornasse administrável ${ }^{14}$.

$\mathrm{Na}$ tentativa de prevenir a rubéola e a SRC, foram adotadas como estratégias chaves a introdução da vacina contra a rubéola nos programas de imunização de crianças e a realização de campanhas de vacinação de homens e mulheres, adolescentes e adultos. Algumas práticas aconselháveis nos programas de imunização são incluídas: questionar se estão grávidas, não vacinando aquelas que dizem estar, explicar sobre o risco para o feto, e aconselhar as mulheres vacinadas a não engravidar durante três meses seguidos da vacinação 4,17-20.

Desde a permissão da vacina da rubéola em 1969, a ocorrência da doença nos Estados Unidos decresceu $99 \%$ até o ano de 1999. O número de casos de SRC também se declinou, afetando desproporcionalmente crianças nascidas de mães estrangeiras. De 1997 a 1999, o total de $81 \%$ de crianças registradas com CRS eram hispânicas, e 92\% eram nascidas de mães estrangeiras ${ }^{4}$.

Em 1979, iniciou-se o uso exclusivo da vacina de vírus vivo RA 27/3 para a imunização de rubéola nos Estados Unidos. Esta possuía grandes vantagens sobre as outras vacinas usadas no passado, pois produzia anticorpos nasofaríngeos e grande variedade de anticorpos séricos, fornecendo melhor proteção contra reinfecção e assemelhando-se mais estreitamente à proteção conferida pela infecção natural. Atualmente a vacina mais utilizada é a tríplice viral MMR (Measles/Mumps/Rubeola) contendo uma combinação de vírus de sarampo, caxumba e rubéola ${ }^{2}$.

No ano de 1996, a Organização Mundial de Saúde estimou que $36 \%$ dos países-membros ofereciam como rotina a vacinação da rubéola, e em 1999 este valor aumentou para 52\%. Na região das Américas $89 \%$ dos países já utilizavam a vacina da rubéola como rotina ${ }^{4}$.

Muitos países ainda não adquiriram este programa, outros o implementaram recentemente, e enquanto isso muitos adultos de uma extremidade a outra do mundo permanecem susceptíveis à doença ${ }^{4}$.

A imunização inadvertida de mulheres grávidas soronegativas com a vacina RA 27/3 raramente produz infecção fetal (1-2\%) e não causa anomalias congênitas ou manifestações da síndrome da rubéola congênita ${ }^{4}$.

De janeiro de 1971 a abril de 1989, o CDC acompanhou 321 mulheres que sabiam ser susceptíveis a rubéola e que foram vacinadas três meses antes ou três meses após a concepção. Noventa e quatro mulheres receberam a vacina HPV - 77 ou Cendehill, uma recebeu a vacina de tipo desconhecido, e duzentos e vinte e seis receberam a vacina RA 27/3. Nenhuma das 324 crianças nascidas dessas mães tiveram malformação compatível com a infecção de rubéola congênita, mas cinco tiveram evidência de infecção da rubéola subclínica, duas das quais foram expostas a vacina RA 27/3. Baseados nestes dados, o risco estimado para sérias malformações atribuídas a vacina RA $27 / 3$ é de zero a $1.6 \%{ }^{4}$.

Entretanto, por causa do risco teórico insubstancial, e porque é impossível provar que o risco da síndrome da rubéola congênita após vacinação é 
zero, estabelece uma contra indicação para a administração da vacina em gestantes e mulheres que desejam engravidar no mesmo mês da vacinação ${ }^{4}$. Devido ao fato de apresentar um risco consideravelmente baixo, a vacinação inadvertida em gestantes não deve ser uma razão de interrupção da gravidez ${ }^{4,21,22}$.

Outro estudo importante neste aspecto referese à investigação prospectiva de Levichek, do programa de mães de risco da Universidade de Toronto. A análise incluiu 94 mulheres vacinadas antes de saberem do seu estado gestacional. Um grupo controle de mulheres grávidas foi combinado para idade, tabagismo, uso de álcool e drogas de rua. Os resultados não mostraram aumento da taxa de malformações nem diferenças significativas na taxa de perdas da gravidez ou no peso ao nascimento entre os dois grupos. Os marcos do desenvolvimento da criança e o momento em que elas falaram sua primeira palavra também foram semelhantes. A única diferença significativa nos resultados da gravidez está na taxa mais alta de interrupção da gravidez no grupo de casos, em que sete mulheres sofreram a abortamento comparando com nenhuma do grupo controle ${ }^{23}$.

O Comitê de Aconselhamento de Práticas de Imunização (ACIP) recomendava a contra-indicação da vacina da rubéola por um período de três meses antes e três meses depois da concepção, desde $1977^{25}$. Já em 18 de outubro de 2001, após a análise dos dados de diversas fontes, indicando não terem sido identificados casos de SRC em crianças que nasceram de mulheres vacinadas inadvertidamente neste período, fez com que o ACIP encurtasse este período recomendado de vacinação antes ou após o período gestacional para vinte e oito dias ${ }^{25}$.

Em pesquisa epidemiológica no interior de São Paulo foram acompanhadas 26 mulheres vacinadas durante o pré-natal por serem suscetíveis à rubéola. Nesse grupo a taxa de aborto foi de $15,38 \%{ }^{26}$.

Em estudo realizado na Universidade Federal do Rio Grande do Sul, com o objetivo de avaliar a ocorrência da SRC em mulheres que foram vacinadas contra a rubéola e que não sabiam que estavam grávidas, ou que engravidaram até 30 dias após a vacinação, foram coletados 152 amostras sorológicas de bebês, filhos de mães susceptíveis. Um total de 10 bebês $(6,3 \%)$ apresentou presença de anticorpos IgM anti-rubeola, ou seja foram infectados pelo vírus vacinal durante a gestação. Nenhum deles apresentou defeitos congênitos relacionados à rubéola ${ }^{27}$.

Diversos grupos de especialistas reafirmaram a segurança da vacinação inadvertidamente em gestantes ${ }^{28-33}$.
O grupo técnico assessor para Doenças ImunoPreveníveis (TAG) na Região das Américas recomendou em 2000, reafirmando essa recomendação em 2004, que: "Estão disponíveis dados contundentes que documentam a ausência de qualquer tipo da vacina contra a rubéola durante a gravidez. Para mulheres que tem sido vacinadas e posteriormente se diagnostica que estavam grávidas durante a vacinação, não se recomendam o aborto. Não é necessário aconselhar as mulheres para evitar engravidar depois de receber a vacina contra a rubéola já que não há risco conhecido de resultados adversos para o feto" ${ }^{29,31}$.

O Ministério da Saúde recomendou, para a campanha nacional de vacinação contra a rubéola realizada nos meses de agosto e setembro de 2008, a manutenção do prazo que já vem sendo adotado desde 2001 na rede de serviços e nas campanhas de vacinação, ou seja, não vacinar a mulher grávida e evitar a gravidez por 30 dias após ter recebido a vacina contra a rubéola ${ }^{34}$.

\section{COMENTÁRIOS FINAIS}

Diante do grande acometimento de rubéola em gestantes, provocando deficiência auditiva e outros comprometimentos no recém-nascido, ressalta-se a importância da vacinação contra a rubéola em crianças e jovens, principalmente do sexo feminino, assim como programas de orientações, para que toda a população seja conscientizada da importância da prevenção desta doença.

Todas as mulheres de idade fértil que apresentam probabilidades de estarem grávidas deveriam se certificar que não estão antes de tomar a vacina da rubéola, mesmo diante do pequeno risco de infecção congênita. Desta forma, será contra indicada a administração da vacina e a mãe se livrava da incerteza da possibilidade de ter um bebê com a SRC.

Mulheres gestantes, vivendo situações que provocam ansiedade de forma intensa e prolongada, como a vivenciada pela vacinação contra a rubéola durante a gravidez, podem se tornar mais vulneráveis a complicações por comprometerem suas defesas orgânicas e psíquicas.

Estudos anteriores aconselhavam que a mulher não engravidasse durante três meses após receber a vacina contra rubéola. Atualmente é recomendado que a gravidez seja adiada por um mês depois da vacinação. Considera-se esta mudança muito importante porque assim, muitas mulheres podem antecipar o seu desejo da maternidade.

Outra questão importante é o que se refere aos acometimentos aos quais não são percebidos prontamente ao nascimento. Por isso deve ser dada importância aos Programas de Triagem Auditiva 
Neonatal Universal, que apresenta como objetivo a realização da triagem auditiva em todos os recémnascidos e não apenas nos de risco a fim de minimizar os efeitos da deficiência auditiva na criança.

Sabe-se ainda que os seis primeiros anos de vida são considerados de importância essencial para o desenvolvimento normal da linguagem, que se dá em conformidade às atividades pré-linguísticas a partir dos sinais auditivos recebidos Portanto, quanto mais precoce for o diagnóstico da deficiência auditiva, com consequente intervenção e habilitação, melhores serão os prognósticos e as condições para o desenvolvimento global da criança.

Os levantamentos realizados por este estudo permitiram concluir que ainda há um grande caminho a ser percorrido em prol da erradicação da rubéola no Brasil, bem como a diminuição dos riscos de surdez neurossensorial causados pela SRC.

Observa-se que embora o risco da SRC após a imunização seja pequeno, é necessário assegurar a imunidade das mulheres em idade fértil, especialmente daquelas com risco mais alto de exposição, visando a prevenção da SRC.

A humanização das unidades de atendimento também se torna um compromisso, já que estudos comprovam que um atendimento mais individualizado e próximo dos pacientes tem maiores chances de conseguir resultados positivos tanto para estes pacientes quanto para a equipe de trabalho envolvida no processo.

\section{ABSTRACT}

Background: although congenital rubella syndrome risk after immunization is low, it is required to assert immunity of women in fertile age, especially those in higher risk of exposure aiming at prevention. Purpose: to elucidate the risk that rubella immunization in the first three months of gestation presents for the newborn hearing. Conclusion: investigations carried out by this study allow us to conclude that there is still a lot to be done in order to eradicate rubella in Brazil, as well as to reduce/decrease risks of neurosensorial deafness caused by CRS.

KEYWORDS: Immunization; Rubella; Pregnancy

\section{REFERÊNCIAS}

1. Segre CAM Perinatologia: fundamentos e prática. São Paulo: Savier; 2002. p. 192-6.

2. Behrman NN. Tratado de pediatria. 14. ed. Rio de Janeiro: Guanabara Koogan; 1994. p. 462-4.

3. Northern JL, Downs MP. Apêndice dos distúrbios auditivos. In: Northern JL, Downs MP. Audição em crianças. 3 ed. São Paulo: Manole; 1989. p.372-92.

4. Center for Disease Control \& Prevention. Control and prevention of rubella: evaluation and management of suspected outbreaks, rubella in pregnant women, and surveillance for congenital rubella syndrome. MMWR. 2001; 50(RR12):1-23.

5. Burgess MA. Gregg's rubella legacy 1941-1991. Med J Austr. 1992; 156(2):138-9.

6. Forrest JM, Turnbull FM, Sholler GF, Hawker RE, Martin FJ, Doran TT, et al. Gregg's congenital rubella patients 60 years later. Med J Austr. 2002; 177(11-12):664-7.

7. Rubéola. March of dimes defects foundation Wilkes Barre [citado 2002 Mai]. Disponível em: URL: http://www.narcesano.org/BibliotecaDeSalud/ informatiuas/rubeola.htm. Acesso em 25 fev 2003.
8. Picazo JJ, Urbina AFO. Diagnóstico serológico de la rubéola. Protocolos de diagnostico serológico clínico: $n^{\circ}$ 3. [periódico on line]. Disponível em: URL: http://www.innogenetics.com. Acesso em 23 fev 2003.

9. De Santis M, Cavaliere AF, Straface G, Caruso A. Rubella infection in pregnancy. Reprod Toxicol. 2006; 21(4):390-8.

10. Brock R, Martinez SMRC. Infecções congênitas. In: Basseto MCA, Brock R, Wajnsztejn R. Neonatologia: um convite à atuação fonoaudiológica. São Paulo: Lovise; 1998. p.171-80.

11. Bloom S, Rguig A, Berraho A, Zniber L, Bouazzaqui N, Zaghloul $\mathrm{K}$, et al. Congenital rubella syndrome burden in Morocco: a rapid retrospective assessment. Lancet. 2005; 365(9454):135-41.

12. Canonaco RS. Síndromes genéticas com repercussões fonoaudiológicas no recém nascido. In: Basseto MCA, Brock R, Wajnsztejn R. Neonatologia: um convite à atuação fonoaudiológica. São Paulo: Lovise; 1998. p.247-52.

13. Naufal J. Gestação de alto risco. In: Basseto MCA, Brock R, Wajnsztejn R. Neonatologia: um convite à atuação fonoaudiológica. São Paulo: Lovise; 1998.p. 35-40. 
14. Centers for Disease Control \& Prevention. Measles, Mumps, and Rubella: Vaccine use and strategies for elimination of measles, rubella, and congenital rubella syndrome and control of mumps: recommendations of the advisory committee on immunization practices (ACIP). MMWR. 1998; 47(RR-8):1-57.

15. Azevedo, MF, Vieira, RM, Vilanova, LCP Desenvolvimento auditivo de crianças normais de alto risco. São Paulo: Plexus; 1995.p.11-4.

16. Zambonato TCF, Bevilacqua MC, Amantini $\mathrm{RCB}$. Síndrome da rubéola congênita relacionada ao período gestacional de aquisição da doença: características audiológicas. Acta ORL. 2006; 24(4):268-71.

17. Andrus JK, Roses PM. Editorial: Elimination of rubella and congenital rubella syndrome in the Américas: another opportunity to address inequities in health. Rev Pan Am Salud Public. 2004; 15(3):145-6.

18. Best JM, Castillo-Solórzano C, Spika JS, Icenogle J, Glasser JW, Gay NJ, et al. Reducing the global burden of congenital rubella syndrome: report of the World Health Organization Steering Committee on research related to measles and rubella vaccines and vaccination, June 2004. J Infect Dis. 2005; 192(11):1890-7.

19. Morice A, Carvajal X, León M, Machado V, Badilla $X$, Reef $S$, et al. Accelerated rubella control and congenital rubella syndrome prevention strengthen measles eradication: the Costa Rican experience. J Infect Dis. 2003; 187(S1):S158-S63.

20. Steibel G, Milan C, Steibel JAP, Cunha Filho EV, Torrens MC, Stucky JM. Prevalência de anticorpos IgG para rubéola em gestantes do Hospital São Lucas da PUCRS, Porto Alegre, Brasil. Scie Medic. 2007; 17(3):115-8.

21. Kroger AT, Atkinson WL, Marcuse EK, Pickering LK. Centers for Disease Control \& Prevention. General recommendation on immunization. MMWR. 2006; 55(RR15):1-48.

22. Sur DK, Wallis DH, O' Conell TX. Vaccinations in pregnancy. Am Far Physician. 2003; 68(2): 299-304.

DOI: 10.1590 / S1516-18462008005000008

RECEBIDO EM: 03/09/2007

ACEITO EM: 07/07/2008

Endereço para correspondência:

Ana Lúcia Pereira de Andrade Dias

Rua Dr. Campolina, 181 ap. 301

Conselheiro Lafaiete - MG

CEP: $36400-000$

Tel: (31) 3761-6590

E-mail: anafga@ hotmail.com
23. Bar-Oz B, Levicheck Z, Moretti ME, Mah C, Andreou S, Koren G. Pregnancy outcome following rubella vaccination: a prospective controlled study. Am J Med Gen A. 2004; 130A(1):52-4.

24. Centers for Disease Control \& Prevention. Current trends rubella vaccination during pregnancy. United States, 1971-1982. MMWR. 1983; 32(33):429-32,437.

25. Centers for Disease Control \& Prevention. Notice to readers: revised ACIP recommendation for avoiding pregnancy after receiving a rubellacontaining vaccine. MMWR. 2001; 50(49):1117.

26. Ozaki LMTR, Feracin JCF, Simo AKK. Campanha de vacinação contra a rubéola: mães e filhos correm riscos? Rev Enferm UERJ. 2004; 12(1):60-5.

27. Minussi L, Nascimento CR, Momino W, Sanchotene MLC, Enéas LV, Bercini $M$, et al. Avaliação prospectiva de gestantes vacinadas contra a rubéola no sul do Brasil. Scie Médic. 2007; 17(3):119-23.

28. Colares SM. Editorial: Rubéola congênita: um risco prevenível. Scie Medic. 2007; 17(3):114.

29. Organización Panamericana de la Salud, XIV Reunión del Grupo Técnico Asesor em Enfermidades Prevenibles por Vacunación. Foz do Iguaçu, Paraná, Brasil, 2-4 Octubre; 2000.

30. Boletín Informativo del Programa Ampliado de Inmuzaciones. Reunión del Grupo Especial de Expertos em Rubéola y Sarampión. 26(2):1-4.

31. Organización Panamericana de la Salud, XVI Reunión del Grupo Técnico Asesor em Enfermidades Prevenibles por Vacunación. Distrito Federal, México, 3-5 Noviembre; 2004.

32. Hamkar $R$, Jalilvand $S$, Abdolbaghi $M H$, Esteghamati AR, Hagh-Goo A, Keramat $\mathrm{NJ}$, et al. Inadvertent rubella vaccination of pregnant women: evaluation of possible transplacental infection with rubella vaccine. Vaccine. 2006; 24(17):3558-63.

33. Badilla X, Morice A, Avila-Aguero ML, Sáenz E, Cerda I, Reef S, et all. Fetal risk associated with rubella vaccination during pregnancy. Pediatr Infect Dis J. 2007; 26(9):830-5.

34. Brasil. Ministério da Saúde. Informe Técnico no 02. Campanha nacional de vacinação contra a rubéola-2008. Vacinação contra rubéola: gestantes vacinadas inadvertidamente (GVI). Disponível em: URL: http:// portal.saude.gov.br/portal/arquivos/pdf/ informe_rubeola2.pdf.

35. Ozaki LMTR, Shimo AKK. O significado da vacina contra rubéola para as mulheres grávidas. [periódico online] Rev Latino-Am Enferm. 2007; 15(4). Disponível em: URL: http://www.scielo.br/pdf/ rlae/v15n4/pt_v15n4a02.pdf. 